\title{
A Clinical Report on Speech Production of Cochlear Implant Users
}

\author{
P. W. Dawson, P. J. Blamey, S. J. Dettman, L. C. Rowland, E. J. Barker, E. A. Tobey, \\ P. A. Busby, R. C. Cowan, and G. M. Clark
}

Objective: The aim was to assess articulation and speech intelligibility over time in a group of cochlear implant users implanted at 8 yr or over. The hypothesis was that the postoperative speech production performance would be greater than the preoperative performance.

Design: A test of intelligibility using sentences and an articulation test measuring non-imitative elicited speech were administered to 11 and 10 subjects, respectively, who were implanted with the 22-electrode cochlear implant. Nine subjects received both tests. Age at implantation ranged from 8 yr to 20 yr and implant use ranged from 1 yr to 4 yr 5 mo.

Results: For both the intelligibility and articulation tests roughly half of the subjects showed significant improvements over time and group mean postoperative performance significantly exceeded preoperative performance. Improvements occurred for front, middle, and back consonants; for stops, fricatives, and glides and for voiceless and voiced consonants.

Conclusions: Despite being deprived of acoustic speech information for many childhood years, roughly half of the patients assessed showed significant gains in speech intelligibility and articulation postimplantation. The lack of a control group of non-implanted patients means that we cannot separate out the influence of the implant on speech production from other influences such as training and tactile-kinaesthetic feedback.

(Ear \& Hearing 1995;16;551-561)

Poor speech intelligibility is commonly reported for profoundly hearing-impaired children (Markides, 1970; McGarr, 1983; Monsen, 1978; Osberger \& McGarr, 1982; Smith, 1975). Osberger and McGarr (1982) estimate that only one in five words is understood by a listener unfamiliar with the speech of profoundly hearing-impaired speakers. Several factors appear to contribute to their poor speech intelligibility. Segmental errors associated with consonant and vowel production are readily apparent (Carr, 1953; Geffner, 1980; Hudgins \& Numbers,

Cochlear Implant Clinic (P.W.D., S.J.D., L.C.R., E.J.B.), Royal Victorian Eye and Ear Hospital, East Melbourne, Australia; Department of Otolaryngology (P.J.B., P.A.B., R.C.C., G.M.C.), University of Melbourne, East Melbourne, Australia
1942; Markides, 1970; Osberger \& McGarr, 1982; Smith, 1975). Consonant errors include substitutions, omissions, and distortions. Substitutions of visible, front consonants for less visible, back consonants often are observed. Inaccurate voiced/voiceless distinctions contribute to the consonantal errors and may be linked to deviant breathing patterns (Forner \& Hixon, 1977; Metz, Whitehead, \& Mashie, 1982; Whitehead \& Barefoot, 1980). Vowel production is characterized by a higher proportion of errors for sounds requiring high or midtongue heights than low-tongue heights (Nober, 1967; Smith, 1975). Front vowels are produced less accurately than back vowels (Osberger \& McGarr, 1982; Smith, 1975). In addition, suprasegmental features of fundamental frequency, intensity, and duration are abnormal in profoundly hearing-impaired speakers. Abnormally high fundamental frequencies and intensities appear in combination with abnormally long utterances (Osberger \& McGarr, 1982).

Speech intelligibility appears to be influenced by the amount of residual hearing. For example, Boothroyd (1985) reports speech intelligibility is significantly lower in persons with a hearing impairment of 115 to $124 \mathrm{~dB} \mathrm{HL}$ than in persons with hearing impairments between 105 to $114 \mathrm{~dB}$ HL. Comparisons of speech intelligibility as a function of age and hearing impairment led Boothroyd (1985) to conclude that $5 \mathrm{~dB}$ of residual hearing may be as effective as $1.5 \mathrm{yr}$ of speech remediation upon speech intelligibility. Restoration of hearing, albeit limited, via cochlear implantation appears to positively influence speech intelligibility in some children using multichannel cochlear implants (Osberger, Maso, \& Sam, 1993; Staller, 1990; Staller et al., 1991; Tobey et al., 1991a). For example, the measured speech intelligibility of sentences for 27 children improved from $18.1 \%$ preoperatively to $33.5 \%$ after 1 year's use with the multichannel device (Tobey et al., 1991a). This study used experienced listeners to assess sentence intelligibility. Typically studies on the intelligibility of deaf children report higher scores for experienced listeners than for naive listeners (e.g., McGarr, 1983; Monsen, 1978). The mean postoperative score of the implanted children in the Tobey et al. (1991a) study was very similar to means obtained by experienced listeners judging 
sentence material for profoundly hearing-impaired children in other studies with a mean pure-tone average loss in the better ear of 95 to $99 \mathrm{~dB} \mathrm{HL}$ (Markides, 1970; McGarr, 1983). The mean speech intelligibility scores for sentences for a group of children with early onset of deafness (before age 4) using the 3M/House single-channel implant $(n=8)$ and using the 22-electrode cochlear implant $(n=12)$ at the most recent postoperative assessment were $16 \%$ and $18 \%$, respectively (Osberger et al., 1993). The lower scores may be explained by factors such as differences in the sentence assessment material, and the use of inexperienced listeners.

Kirk and Hill-Brown (1985) reported significant increases in the accuracy of many non-segmental and segmental skills for both imitated and spontaneous speech of 2- to 18-yr old profoundly hearingimpaired children using single channel cochlear implants. Increased accuracy of segmental aspects of elicited speech were evident in children using the 22-electrode cochlear implant (Geers \& Tobey, 1992; Tobey et al., 1991a; Tobey \& Hasenstab, 1991; Tye-Murray \& Kirk, 1993). An increased repertoire of sounds was also produced by profoundly hearingimpaired children using this device (Geers \& Tobey, 1992; Osberger et al., 1991; Tobey et al., 1991b).

Speech performance in the profoundly hearing impaired tends to plateau in late childhood (Boothroyd, 1985; Markides, 1970; McGarr, 1987). Previous implant research suggests that prelinguistically deafened adolescents are less likely to show gains in speech production postimplantation than younger prelinguistically deafened implantees. Osberger et al. (1993) reported a trend toward better speech intelligibility for patients with early onset of deafness who were implanted before age $10 \mathrm{yr}$. Kirk and Hill-Brown (1985) found that the youngest group of single-channel implantees ( 2 to $5 \mathrm{yr}$ ) revealed the most gains in speech production. Similarly, Tobey et al. (1991a) reported that a greater percentage of younger patients ( 2 to $9 \mathrm{yr}$ ) than older patients (10 to $17 \mathrm{yr}$ ) using the 22-electrode implant showed speech production gains.

Improvements were, however, evident in the production of nasal and alveolar consonants but not vowel production in three prelingually deafened subjects (two adults and one adolescent) following specific, short-term training with the 22-electrode cochlear implant (Busby, Roberts, Tong, \& Clark, 1991). Targets were produced in isolation and in differing positions within syllables. They were trained on imitation following an auditory-visual model and on demand without a model. These improvements in consonant production occurred without corresponding increases in perception of nasality and alveolar consonants. The authors suggested that the production gains were therefore probably due to the use of tactile-kinaesthetic feedback.

In light of the previous research suggesting little improvement in speech production in the profoundly hearing impaired after late childhood, the present study looks specifically at changes in an older group of implanted subjects with early onset of profound deafness. Can children who are deprived of acoustic information for many years in childhood show improvements in speech production postimplantation? The group of subjects in this study included children implanted at $8 \mathrm{yr}$ or older, adolescents and two prelinguistically deafened adults. All subjects had been implanted with the 22-electrode multichannel cochlear implant at the Royal Victorian Eye and Ear Hospital and had received postoperative assessments over at least a 12-mo period. The paper examines changes in intelligibility and elicited phonemic speech skills. The data complement previous reports of speech production performance in children with cochlear implants and are unique in several aspects. First, the study measures phonemic changes in non-imitative, elicited speech, whereas previous studies on implanted children (e.g., Geers \& Tobey, 1992; Kirk \& Hill-Brown, 1985; Tobey et al., 1991a) report on elicited speech production skills measured at a phonetic level via syllable imitation. Second, the data represent speech production performance over longer time periods than previously reported. Finally, this report examines speech production data from an individual, as well as group, perspective. The question of what contribution the implant made to changes in speech production (compared to a control group using hearing aids or alternative assistive devices) was not investigated directly. Comparisons with previously reported data on implanted children and children using hearing aids andlor tactile aids can be made, however. The following specific questions were addressed:

1) Does the group mean performance improve from pre- to postoperative testing?

2) Does performance improve over time for individuals?

3) Do some types of speech sounds change postimplantation more than others?

\section{Method}

\section{Patients}

The group of subjects described here includes all children implanted at 8 yr or older for whom elicited speech production data had been collected for over 12 mo postoperatively. Table 1 gives individual details and means for 12 patients, including two prelinguistically deafened adults. The educational program of four of the patients was total communication, in which signed English was used. Several of 
TABLE 1. Patient details: ages and durations are shown in years and months.

\begin{tabular}{|c|c|c|c|c|c|c|c|c|c|}
\hline \multirow[b]{2}{*}{ Patient } & \multirow[b]{2}{*}{ Etiology } & \multirow[b]{2}{*}{ Onset of Loss } & \multirow{2}{*}{$\begin{array}{l}\text { Duration of } \\
\text { Profound } \\
\text { Deafness }\end{array}$} & \multirow{2}{*}{ Educational Program } & \multirow{2}{*}{$\begin{array}{l}\text { Age at Im- } \\
\text { plantation }\end{array}$} & \multirow[b]{2}{*}{ Sex } & \multirow{2}{*}{$\begin{array}{l}\text { PTA } \\
\text { Hearing } \\
\text { Loss } \\
(\mathrm{dB} \mathrm{HL})\end{array}$} & \multicolumn{2}{|c|}{$\begin{array}{l}\text { Duration of Implant } \\
\text { Use (mo) }\end{array}$} \\
\hline & & & & & & & & Artic. & Intell. \\
\hline 23 & Meningitis & $1 \mathrm{yr} 4 \mathrm{mo}$ & 12 y $7 \mathrm{mo}$ & Cueing supplement & $13 \mathrm{yr} 11 \mathrm{mo}$ & M & 110 & & 3 yr 4 mo \\
\hline 35 & Meningitis & 3 yr 3 mo & 6 yr 9 mo & Auditory/oral & $10 \mathrm{yr} 2 \mathrm{mo}$ & $M$ & 115 & & $1 \mathrm{yr} 8 \mathrm{mo}$ \\
\hline 61 & Usher's syndrome & Congenital & $14 \mathrm{yr} 11 \mathrm{mo}$ & Cueing supplement & $14 \mathrm{yr} 11 \mathrm{mo}$ & $F$ & 115 & 4 yr 5 mo & $3 \mathrm{yr}$ \\
\hline 62 & Usher's syndrome & Congenital & 19 yr 9 mo & Cueing supplement & 19 yr 9 mo & $\mathbf{F}$ & 115 & 2 yr 11 mo & $1 \mathrm{yr} 10 \mathrm{mo}$ \\
\hline 71 & Unknown & Congenital & $8 \mathrm{yr}$ & Cueing supplement & $8 \mathrm{yr}$ & $\mathbf{F}$ & 110 & $1 \mathrm{yr} 1 \mathrm{mo}$ & 2 yr 6 mo \\
\hline 76 & Meningitis & 2 yr 4 mo & 5 yr $10 \mathrm{mo}$ & Auditory/oral & 8 yr 2 mo & $\mathbf{F}$ & 112 & 2 yr 6 mo & $1 \mathrm{yr} 1 \mathrm{mo}$ \\
\hline 91 & Usher's syndrome & Congenital & $20 \mathrm{yr} 1 \mathrm{mo}$ & Total communication & $20 \mathrm{yr} 1 \mathrm{mo}$ & $M$ & 120 & 1 yr 6 mo & $7 \mathrm{mo}$ \\
\hline 93 & Meningitis & $3 \mathrm{yr}$ & 14 yr $7 \mathrm{mo}$ & Auditory/oral & 17 yr $7 \mathrm{mo}$ & M & 115 & 3 yr 2 mo & 3 yr 2 mo \\
\hline 94 & Usher's syndrome & Congenital & 16 yr $5 \mathrm{mo}$ & Total communication & 16 yr 5 mo & $F$ & 104 & 3 yr 3 mo & 3 yr 3 mo \\
\hline 104 & Unknown & Congenital & 17 yr $7 \mathrm{mo}$ & Auditory/oral & 17 yr 7 mo & $M$ & 113 & 2 yr 5 mo & 2 yr $5 \mathrm{mo}$ \\
\hline 106 & Unknown & 4 yr progressive & 7 yr $1 \mathrm{mo}$ & Total communication & $11 \mathrm{yr} 1 \mathrm{mo}$ & M & 103 & 1 yr 2 mo & \\
\hline
\end{tabular}

the patients who used oral communication received a cued speech supplement. All of the subjects became profoundly deaf before age 5. Stoel-Gammon and Dunn (1985) show that children do not stabilize their phonological systems until after the age of $4 \mathrm{yr}$. Duration of implant use represents the time between implantation and the last postoperative assessment. Since the last assessments for articulation and intelligibility occurred at very different times for several patients, duration of implant experience for individual subjects has been provided for both production assessments.

The numbering of patients is according to the chronological order in which they were implanted. Some of the speech production results for children 71 and 76 have been reported previously (Busby et al., 1989; Dowell et al., 1991); however, more recent data for these children are included in this report.

Preoperative average hearing loss in the better ear is expressed as pure-tone average hearing loss (PTA) in dB HL. Most of the preoperative evaluations were conducted using high-gain, post-auricular hearing aids that the patients consistently used prior to implantation. Patients' preoperative aided hearing thresholds were out of the $70 \mathrm{~dB}$ SPL speech range (Byrne, 1977) for frequencies above $1.5 \mathrm{kHz}$. Child 93 used a two-channel vibrotactile device, the Tactaid II (Audiological Engineering, Somerville, MA). Child 76 continued to use a hearing aid on the unimplanted ear following surgery. Postoperative speech production assessments for this child were conducted in the combined condition (implant plus hearing aid). Separate evaluations of the implant and hearing aid were not conducted in order to reduce the assessment time and to assess changes in speech production under conditions used in everyday communication.

Patients were implanted with the 22-electrode cochlear prosthesis manufactured by Cochlear Pty. Ltd. (Clark et al., 1987). Most of the patients had 15 or more electrodes activated. Children 63 and 93 had 9 and 5 electrode channels activated, respectively, due to partial insertion and/or unpleasant sensations on some electrodes. For the majority of patients, the initial speech processing strategy encoded the fundamental frequency (F0) as pulse rate, estimates of the first and second formant frequencies (F1 and F2) as electrode positions, and amplitude as current level (Blamey, Dowell, Clark, \& Seligman, 1987b). Shortly after October 1989, patients received the MSP processor using a multipeak strategy encoding F0, F1, and F2, as well as three high-frequency bands: 2.0 to $2.8 \mathrm{kHz}$ (Band 3), 2.8 to $4 \mathrm{kHz}$ (Band 4), and frequencies above $4 \mathrm{kHz}$ (Band 5), onto three fixed basal electrode positions (Skinner et al., 1991). Amplitudes of signals in these three regions are measured and the encoding strategy generates four pulses of electrical stimulation per stimulus period. During voiced speech, four electrodes are selected: the two basal electrodes allocated to Bands 3 and 4 and two electrodes allocated to the estimated F1 and F2. During unvoiced speech, four electrodes are again selected but the most basal electrode is allocated to Band 5 , in addition to another basal electrode allocated to either Band 4 or 3 and electrodes allocated to F1 and F2. These four electrodes are stimulated non-periodically at an average rate higher than most $F 0$ frequencies when the signal is judged to be unvoiced. Thus, the MSP processor and multipeak strategy provide more information regarding identification of voicing and fricatives than previously provided by the WSP speech processor which coded F0, F1, F2, and the amplitudes of F1 and F2. Patients 63 and 93 used the MSP processor with the older F0F1F2 strategy due to a reduced number of electrodes. 


\section{Habilitation}

Patients received habilitation additional to that provided in their educational programs as well as consultative support and regular fine tuning or "mapping" of the electrodes. Usually individual sessions of approximately $1 \mathrm{hr}$ per week were provided regularly during pre- and postoperative periods.

The primary focus of habilitation was the use of audition in the development of spoken communication. Management incorporated the development of language, speech perception, and speech production skills. A parent attended some of the therapy sessions and was guided in how to optimize the use of audition in his/her interaction with the child. Close liaison with teachers in the child's educational setting was fostered.

\section{Assessments}

Speech intelligibility was assessed using the procedure of McGarr (1983). Patients were asked to read 36 sentences varying in length and contextual cues. Speech intelligibility was determined from the number of key monosyllabic words in the sentences correctly identified by normally hearing listeners. The key words were chosen from a corpus of words produced by deaf children in Smith's (1975) study and represented the 18 words ranked highest and lowest for speech intelligibility. Half of the sentences had high contextual information (e.g., The flag is red, white, and blue), and half had low contextual information (e.g., Get the cake).

The listeners were clinicians (either speech pathologists or audiologists) familiar with the speech of hearing-impaired children. They were not shown the set of sentences. A total of 12 listeners were used to score the 38 sets of McGarr sentences. The authors acknowledge that it would have been ideal, but less practical, to have at least 38 experienced listeners to eliminate the possibility of listeners remembering some of the test material. Although each judge listened to three or four sets of sentences, these sentences were not produced by the same patient and a 6-mo time period generally elapsed between the scoring of two sets of sentences. The listeners heard the sentence sets in a random order so that any listener learning effects did not affect the speaker learning rate.

The Test of Articulation Competence (Fisher \& Logemann, 1971) was used to measure the articulation of 24 consonants, 16 vowels (including 4 diphthongs), and 23 consonant blends (see Appendix 1). Each consonant was represented once in the initial, medial, and final positions of single-word utterances. Patients were required to say the series of target words represented by pictures. Responses were broadly transcribed from videotape recordings
TABLE 2. Preoperative and latest postoperative percentage scores on the sentence intelligibility test are given for each individual.

\begin{tabular}{|c|c|c|c|c|c|c|}
\hline \multirow[b]{2}{*}{ Patient } & \multicolumn{2}{|c|}{ Low Context } & \multicolumn{2}{|c|}{ High Context } & \multicolumn{2}{|c|}{ Total } \\
\hline & Pre & Post & Pre & Post & Pre & Post \\
\hline 23 & 22.2 & 50.0 & 50.0 & 22.2 & 36.1 & 36.1 \\
\hline 35 & 0.0 & $55.6^{c}$ & 0.0 & $66.7^{c}$ & 0.0 & $61.1^{c}$ \\
\hline 61 & 5.6 & 38.9 & 22.2 & $50.0^{b}$ & 13.9 & $44.4^{b}$ \\
\hline 62 & 27.8 & 38.9 & 27.8 & 61.1 & 27.8 & 50.0 \\
\hline 63 & 11.1 & 27.8 & 11.1 & $66.7^{c}$ & 11.1 & $47.2^{b}$ \\
\hline 71 & 16.7 & 33.3 & 25.0 & 61.1 & 20.8 & $47.2^{a}$ \\
\hline 76 & 22.2 & 16.7 & 16.7 & 27.8 & 19.4 & 22.2 \\
\hline 91 & 11.1 & 11.1 & 11.1 & 22.2 & 11.1 & 16.7 \\
\hline 93 & 16.7 & $66.7^{b}$ & 50.0 & $94.4^{b}$ & 33.3 & $80.6^{c}$ \\
\hline 94 & 5.6 & 11.1 & 16.7 & 27.8 & 11.1 & 19.4 \\
\hline 104 & 5.6 & 11.1 & 22.2 & $77.8^{c}$ & 13.9 & $44.4^{b}$ \\
\hline 106 & & & & & NA & \\
\hline
\end{tabular}

NA indicates that the production test was not administered. Significance levels refer to the chi-square analysis of all pre- and postoperative data for an individual. ${ }^{b} p<0.05{ }^{b} p<$ $0.01 i^{c} p<0.001$

by a listener familiar with the speech of the patient. In most cases, the listener was the clinician working with the patient.

Not every patient received both tests. The intelligibility test was administered to 11 of the 12 patients. Child 106 did not have appropriate reading skills to complete the measure of speech intelligibility. The articulation test was administered to 10 of the 12 patients. Articulation results for child 35 on the Edinburgh Articulation Test (Anthony, Bogle, Ingram, \& Isaac, 1971) were reported by Busby et al. (1989) and more recent data using the Test of Articulation Competence has not been collected. Patient 23 was also assessed only on the Edinburgh Articulation Test. Table 2 indicates which tests were administered to each patient.

Given that utterances may be transcribed differently by different listeners (Gold, 1980; Shaw \& Coggins, 1991; Shriberg \& Lof, 1991), interlistener and intralistener reliability estimates for a subsample of the data for the two tests were obtained. Interlistener reliability was measured by having a second experienced judge assess 6 of a total of 40 articulation samples ( 3 pre- and 3 postimplantation) and 7 of a total of 38 speech intelligibility samples (4 pre- and 3 postimplantation). Pearson product moment correlation coefficients were 0.93 and 0.90 for the overall scores on the tests of articulation and speech intelligibility, respectively. The second judge also assessed the subset of samples twice to provide an estimate of intralistener reliability. Coefficients of 0.88 and 0.97 were obtained for the articulation and speech intelligibility tests respectively. Two speech-language pathologists served as second judges for the articulation test and four audiologists served as second judges for the speech intelligibility measures. 


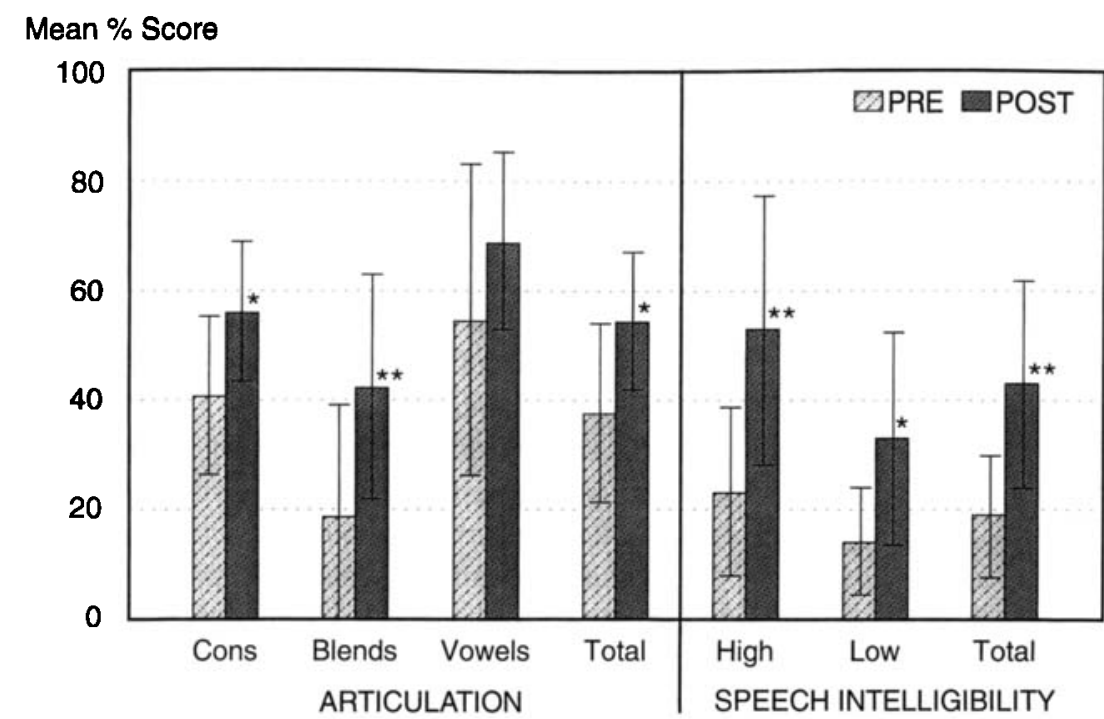

Figure 1. Phoneme articulation and sentence intelligibility scores for groups of $\mathbf{1 0}$ and $\mathbf{1 1}$ patients, respectively. Mean scores for single consonants, consonant blends, and vowels and for the intelligibility of high- and lowcontext sentences are shown in addition to total scores. Significance levels refer to onetailed, paired t-test comparisons of the latest pre- and postoperative mean scores. ${ }^{*}$ indicates $p<0.05$; $* *$ indicates $p<0.01$. Error bars show \pm 1 SD from the mean.
Speech perception skill was assessed to determine whether those patients who show the best perception ability with the implant show the greatest gains in production. The Picture Vocabulary Test (Plant, 1984) was administered at the last postoperative interval in which articulation and intelligibility scores were obtained. This test requires the sound-alone recognition of monosyllabic words in a 12-alternative forced-choice format. The items in the test are "shoe, fork, tree, car, bird, key, dog, book, duck, bed, hat, and fish." Each item was presented twice and the patient responded by pointing to pictures.

\section{Data Analysis}

The $t$-test for dependent samples was used with a one-tailed criterion to test the directional hypothesis that the group mean postoperative performance would be significantly greater than the group mean preoperative performance.

For individual patients, a chi-square statistic $(p<$ 0.05 ) was used to assess whether the scores obtained at different times were significantly different. The data were visually inspected to determine whether the changes represented gains over time. The criteria used to determine whether a gain in performance had occurred were: a) the final score must be greater than the initial score, b) the chi-square must be significant at $p<0.05$ (two-tailed test), and c) a general upward trend for scores should occur over time. This procedure was used in preference to a linear regression or correlation analysis because the trends in the data are not necessarily linear, and the chi-square test is more appropriate for binomially distributed proportional data than the parametric alternatives that assume a normal distribution of scores.

\section{REsults}

\section{Speech Intelligibility: Group Results}

Mean group performance (for total scores) of 11 patients on the latest postoperative assessment was significantly higher than the performance on the preoperative assessment $(p<0.01)$ as shown in Figure 1. Significant group improvements were found for both the high and low context intelligibility sentences. The error bars shown reveal considerable variation in performance among patients.

\section{Speech Intelligibility: Individual Results}

Preoperatively, scores ranged from $0 \%$ to $36 \%$. Postoperatively, scores ranged from $19 \%$ to $81 \%$, but the majority of patients received postoperative scores less than $50 \%$ (see Table 2). Figure 2 provides an example of an individual's longitudinal performance. Patient 61 had the greatest number of data assessments and a long duration of implant use. For this patient there were significant gains over time from the preoperative assessment to the latest assessment at 36 mo postimplant for the total intelligibility score. Table 2 shows that 6 of the 11 patients tested $(55 \%)$ showed significant gains in speech intelligibility. The overall scores were higher and more patients showed significant improvements on the high context intelligibility sentences than on the low context sentences.

\section{Test of Articulation: Group Results}

Preoperative group mean performance was compared with postoperative group mean performance for the 10 patients assessed on the articulation test. Figure 1 shows a significant increase over time in the overall accuracy of articulation $(p<0.05)$. Error bars reveal substantial variability in individual per- 


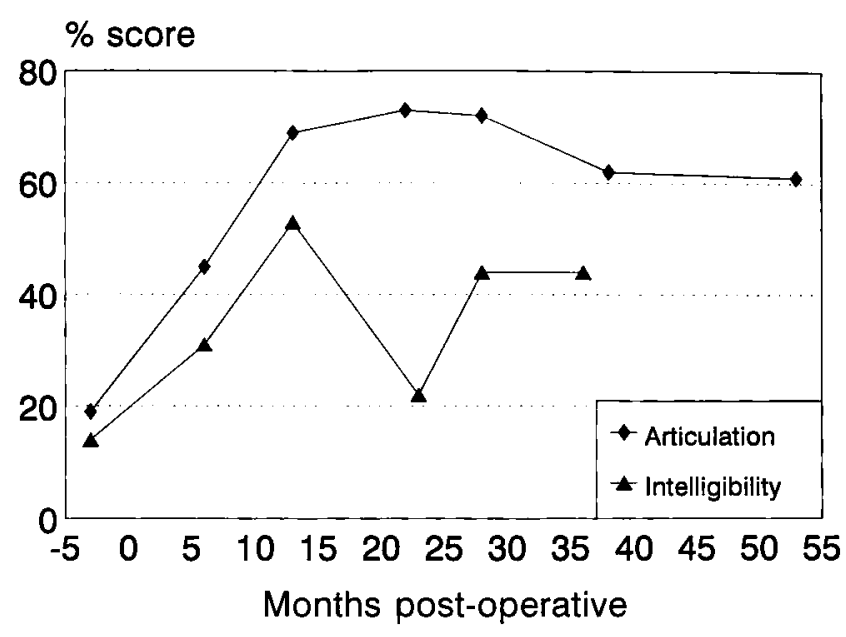

Figure 2. Total percentage scores for the articulation and intelligibility tests for patient 61 . The first data point was 3 mo preimplantation. Age at implantation for this patient was 14 yr 11 mo.

formance. The increase in total performance was mainly attributable to the significant increases in consonant and consonant blend accuracy. The gain in vowel accuracy only just failed to reach significance with $(p=0.053)$. Given the much smaller number of items in the vowel subtest relative to the number of consonants tested, a statistically significant result was less likely. Finer analyses were then conducted on the consonant data. These analyses indicated which types of sounds (according to place, manner of articulation, and voicing categories) were more accurately produced. Data from the most recent preimplant and most recent postimplant assessments were analyzed. Matrices were constructed contrasting the intended target versus the response for consonants in initial, medial, and final positions. Percentages were obtained for each group of consonants by dividing the number of correct responses for consonants in each category by the total number of occurrences possible. A summary of these data is shown in Table 3.

Consonants were examined in three places of articulation: front (including bilabial, labio-dental, and lingua-dental positions), middle (including alveolar and palatal positions), and back (including velar and glottal positions). They were also grouped accordjng to five manner categories; stop, nasal, fricative, affricate and glide, and whether they were voiced or unvoiced. One-tailed chi-square tests were used to test the directional hypotheses that postoperative performance would exceed preoperative performance in each of the initial, medial, and final word positions and across these word positions for the various categories (see Table 3 ).

With the exception of nasals and affricates, there were significant gains in accuracy for each of the consonant categories. Significant increases in accuracy also occurred in each of the three word positions. Consonants produced at the front of the mouth were significantly more accurate than those produced further back in the mouth, regardless of implant status (pre versus postoperative) or position in the word ( $p<0.001$ for a two-tailed chi-square test). Affricates were, by far, the group of consonants that were produced the least accurately.

\section{Test of Articulation: Individual Results}

Preoperatively, total scores on the articulation test ranged from $17 \%$ to $68 \%$. Postoperatively, total scores ranged between $26 \%$ and $70 \%$ (see Table 4). Eight patients scored less than $50 \%$ at the first evaluation, but only two patients (91 and 94) scored less than $50 \%$ at the most recent postoperative

TABLE 3. Percentages of correctly produced consonants on the articulation test for 10 patients, comparing pre- and postoperative performance.

\begin{tabular}{|c|c|c|c|c|c|c|c|c|}
\hline \multirow{2}{*}{$\begin{array}{l}\text { Consonant Position } \\
\text { Implant Status }\end{array}$} & \multicolumn{2}{|c|}{ Initial } & \multicolumn{2}{|c|}{ Medial } & \multicolumn{2}{|c|}{ Final } & \multicolumn{2}{|c|}{ Total } \\
\hline & Pre & Post & Pre & Post & Pre & Post & Pre & Post \\
\hline \multicolumn{9}{|c|}{ Place of articulation } \\
\hline Front & 58.8 & $76.3^{b}$ & 52.5 & $68.8^{a}$ & 50.0 & $67.1^{a}$ & 53.9 & $70.9^{c}$ \\
\hline Middle & 42.7 & $56.4^{a}$ & 31.7 & $45.8^{a}$ & 27.0 & $44.0^{b}$ & 33.9 & $48.8^{\mathrm{C}}$ \\
\hline Back & 56.7 & 70.0 & 22.5 & 30.0 & 23.3 & 40.0 & 33.0 & $45.0^{a}$ \\
\hline \multicolumn{9}{|c|}{ Manner of articulation } \\
\hline Stop & 55.0 & 68.3 & 43.3 & 50.0 & 40.0 & 50.0 & 46.1 & $56.1^{a}$ \\
\hline Nasal & 75.0 & 80.0 & 23.3 & 33.3 & 43.3 & 53.3 & 43.8 & 52.5 \\
\hline Fricative & 48.8 & $68.8^{b}$ & 40.0 & $55.6^{a}$ & 35.0 & $60.0^{c}$ & 41.2 & $61.2^{c}$ \\
\hline Affricate & 15.0 & 20.0 & 15.0 & 10.0 & 10.0 & 15.0 & 13.3 & 15.0 \\
\hline Glide & 52.5 & 70.0 & 42.5 & $75.0^{b}$ & 20.0 & 60.0 & 44.4 & $71.1^{\circ}$ \\
\hline \multicolumn{9}{|l|}{ Voicing } \\
\hline Voiceless & 46.7 & $64.4^{b}$ & 40.0 & 44.4 & 50.0 & $71.3^{b}$ & 45.4 & $59.6^{c}$ \\
\hline Voiced & 53.1 & $66.2^{a}$ & 35.3 & $54.7^{c}$ & 24.2 & $38.3^{b}$ & 37.8 & $53.5^{c}$ \\
\hline Total & 50.5 & $65.5^{c}$ & 37.1 & $50.8^{b}$ & 34.5 & $51.5^{c}$ & 40.8 & $55.9^{c}$ \\
\hline
\end{tabular}

Consonants are grouped according to their production features. Postoperative scores marked with superscripts are significantly higher than the preoperative scores. ${ }^{a} p<0.05 ;{ }^{b} p<0.01 ;$ c $p<0.001$. 
TABLE 4. Preoperative and latest postoperative percentage scores on the articulation test are given for each individual.

\begin{tabular}{|c|c|c|c|c|c|c|c|c|c|}
\hline Patient & \multicolumn{2}{|c|}{ Consonants } & \multicolumn{2}{|c|}{ Blends } & \multicolumn{2}{|c|}{ Vowels } & \multicolumn{2}{|c|}{ Total } & Perception \\
\hline 23 & & & & & & & NA & & 8.0 \\
\hline 61 & 27.3 & $66.7^{b}$ & 4.3 & $39.1^{b}$ & 6.3 & $68.8^{a}$ & 19.0 & $60.9^{b}$ & 63.0 \\
\hline 62 & 33.3 & $72.7^{b}$ & 8.7 & $56.5^{a}$ & 50.0 & 75.0 & 30.5 & $69.5^{b}$ & 19.0 \\
\hline 63 & 24.2 & $66.7^{b}$ & 0.0 & $69.6^{b}$ & 12.5 & 43.8 & 17.1 & $63.8^{b}$ & 17.0 \\
\hline 91 & 53.0 & 46.9 & 34.8 & 17.4 & 81.3 & 68.8 & 53.3 & 43.8 & 21.0 \\
\hline 93 & 69.7 & 62.1 & 65.2 & 65.2 & 62.5 & 62.5 & 67.6 & 62.8 & 29.0 \\
\hline 94 & 24.2 & 28.8 & 0.0 & 4.3 & 50.0 & 43.8 & 22.9 & 25.7 & 17.0 \\
\hline 104 & 48.5 & 54.5 & 8.7 & 30.4 & 50.0 & 93.8 & 43.8 & 55.2 & 8.0 \\
\hline 106 & 42.4 & 46.9 & 23.9 & 47.8 & 81.3 & 75.0 & 44.3 & 51.4 & 42.0 \\
\hline
\end{tabular}

NA indicates that the production test was not administered. Significance levels refer to the chl-square analysis of all pre-and postoperative data for an individual. ${ }^{a} p<0.01 ;{ }^{b} p<0.001$. Percentage word recognition scores are also given.

evaluation. Patient 61 for example showed highly significant improvement in the total articulation score from the pre- to postoperative periods (see Fig. 2). The performance appeared to plateau at about 13 mo postimplantation. Table 4 indicates that 5 of the 10 patients (50\%) showed significant improvement over time.

All of the patients who revealed significant gains for the total score on the articulation test revealed significant improvements for consonant production. Fewer of these patients showed significant improvements over time for consonant blends and vowels.

Nine patients were evaluated on both the articulation and the intelligibility tests. There was a high, significant correlation between individuals' scores on the two tests obtained at corresponding pre- and postimplant time intervals $(r=0.73, p<0.001, n=29$ ).

Sound-alone word recognition percentage scores are shown in Table 4. The scores provided represent the mean of two sets of scores, one obtained at the last postoperative interval in which articulation was measured and the other obtained at the last postoperative interval in which intelligibility was measured. The two sets of scores were very similar and a mean was taken. Several patients did not score significantly above chance ( $8 \%$ is the chance score and scores of less than $17 \%$ are not significantly above chance for $p<0.05$ ).

\section{Discussion}

\section{Preoperative Performance}

The sentence intelligibility prior to implantation in this study (18.6\%) is similar to several previous reports ranging between $18.1 \%$ and $26 \%$ sentence intelligibility for American and British profoundly hearing-impaired speakers (Brannon, 1964; John \& Howarth, 1965; Markides, 1970; Smith, 1975; Tobey et al., 1991a). This is in spite of differences between studies in the mean average hearing loss of the patients, in the experience of the listeners, and in the test material used to assess intelligibility. Similar patterns of segmental errors between the Australian population and other profoundly hearingimpaired speakers of other English dialects are evident preoperatively. Preoperatively, the profoundly hearing-impaired Australian speakers demonstrate initial, medial, and final consonant omissions, consonant cluster errors, vowel substitutions and centralization, and voicing confusions of cognate pairs which contribute to the low scores obtained on the articulation test. Such errors are consistent with the pattern of errors characterizing the speech of profoundly hearing-impaired speakers of other English dialects (Hudgins \& Numbers, 1942; Nickerson, 1975; Osberger \& McGarr, 1982; Smith, 1975). Overall, it would appear this group of profoundly hearing-impaired speakers resembles other populations of profoundly hearing-impaired speakers.

\section{Postoperative Sentence Intelligibility}

The group mean total speech intelligibility score was significantly higher postoperatively than preoperatively. The group average postoperative scores for low and high context sentences were remarkably similar to those reported by McGarr (1983) for experienced listeners judging a group of 20 congenitally hearing-impaired children with a mean puretone average of $98.6 \mathrm{~dB} \mathrm{HL}$. In accordance with McGarr's findings, group mean scores for test words in high context sentences were higher than those for test words in low-context sentences. McGarr reported differences of approximately $16 \%$ for both experienced and inexperienced listeners. In the present study this difference was greater postoperatively than preoperatively (20\% compared with 9\%). A possible explanation is that listeners may use 
contextual information more effectively when the child's intelligibility is higher at the final postoperative assessment rather than preoperatively when it is lower.

Despite the significant group results not all individual patients improved. Fifty-five percent of the patients demonstrated a significant improvement over time in speech intelligibility. A greater number of patients improved on the high context sentences than on the low context sentences.

Significant increases in speech intelligibility postimplant have also been reported for profoundly hearing-impaired children participating in clinical trials of the 22-electrode cochlear implant (Tobey et al., 1991a; Tobey \& Hasenstab, 1991). The group mean performance on speech intelligibility postoperatively in this study was higher than that previously reported for implanted children assessed with the McGarr procedure. Postoperatively, speech intelligibility averaged $42.7 \%$ in this study compared to previous reports of $33.5 \%$ (Tobey et al., 1991a) and 37\% (Tobey \& Hasenstab, 1991). Experienced listeners were used in both studies. The higher speech intelligibility scores observed in this study may be related to increased experience with the implant. Patients in this study averaged 2 yr 4 mo experience compared with the 6 to 12 mo experience in the American studies.

Children participating in the studies conducted by Tobey and her colleagues were younger and experienced a shorter period of profound hearing impairment than the subjects of this study. For example the mean age at implantation of subjects in this study was 14 yr 7 mo compared to 9 yr 8 mo (Tobey et al., 1991a). Mean length of hearing impairment for this study was 13 yr 8 mo versus 6 yr 11 mo in the study by Tobey et al. (1991a). Given the findings of previous studies of implanted children (described in the introductory section) which showed greater speech production gains for the younger children with a shorter duration of deafness, one might have expected lower postoperative intelligibility scores for this study's group. Tobey et al. (1991a) note, however, that the younger children in their study were less proficient than the older children in reading skills which are fundamental to the intelligibility task. This would have resulted in lower than expected pre- and postimplant intelligibility scores.

It is possible that different processing strategies may contribute to the differences observed in speech intelligibility between this and previous implant studies. By the end of 1989 most patients in the current study were using the MSP processor with a multipeak strategy whereas WSP processors were used by the children investigated by Tobey and colleagues (Tobey et al., 1991a, 1991b; Tobey \& Hasenstab, 1991). It is possible the MSP multipeak strategy provides more effective feedback which may be used to alter speech intelligibility.

\section{Postoperative Articulation Scores}

Fifty percent of the patients in this study demonstrated significant improvement over time for the total score on the articulation test. A greater number of patients improved on the consonant and consonant blend inventories than on the vowel inventory suggesting that increases in consonant accuracy provided the main contribution to the overall total score increases. Increased diversity and/or accuracy of consonant production in children with cochlear implants has been observed in several studies (Geers \& Tobey, 1992; Kirk \& Hill-Brown, 1985; Osberger et al., 1991; Tobey et al., 1991a; Tobey \& Hasenstab, 1991). Osberger et al. (1991) and Geers and Tobey (1992) found that the children using the 22 -electrode implant made greater gains over time than matched groups of children using tactile aids or hearing aids. In the latter studies the majority of the children were under $8 \mathrm{yr}$ of age at the time of device fitting. Furthermore, in the other above-mentioned studies more improvements were reported for the younger children than for the older children. In accordance with the present findings however, Tobey et al. (1991a) reported significant increases in the imitation of segmental features for $50 \%$ of the older children (10 to $17 \mathrm{yr}$ ).

A closer examination of the consonant productions in the articulation test revealed improved accuracy from pre- to postoperative assessments across several dimensions. Improvements occurred in all word positions tested: initial, medial, and final. Consonants articulated at the front of the mouth were more accurately produced than the middle and back consonants, which is consistent with the trend observed in previous studies of the speech of hearing-impaired children (e.g., Geffner, 1980; Nober, 1967; Smith, 1975). Consonants produced in the front of the mouth are generally more accurate because they are more visible, the lips are more restrained in movement than the tongue, and fewer sounds are produced in the front than in the middle of the mouth. However, both the visible and the less visible consonants improved postoperatively in this study. This suggests that speechreading cues (mainly lip movements) could not have solely accounted for the changes and that the perceptual cues available through the implant were probably influential. Increased accuracy of visible consonants after use with the 22-electrode cochlear implant was observed in young children by Geers and Tobey (1992). In contrast to the present findings significant increases in accuracy were not observed by Geers and Tobey for consonants in the less visible 
velar and palatal positions. Increased accuracy of consonants in various manner of production categories occurred postoperatively in this study; a finding similar to that of Geers and Tobey (1992). Osberger et al. (1991) found that more children using the 22-electrode implant acquired fricatives, liquids, glides, and voiceless consonants over a 12 -mo period than did the children in the tactile aid or singlechannel cochlear implant groups. Voiced and voiceless consonants were produced more accurately after implant use in the present study. Similarly Geers and Tobey (1992) observed improved production of voiced and voiceless consonants for children after 2 yr of implantation. It must be noted that these other studies used different methods of evaluating speech production than the method used in the present study. Geers and Tobey (1992) analyzed both spontaneous and imitative speech while Osberger et al. (1991) analyzed spontaneous speech samples.

Improvement of consonant production across place, manner and voicing categories is consistent with perceptual studies showing that the MSP and WSP processors convey information useful in recognizing these consonant categories (Blamey, Dowell, Brown, Clark, \& Seligman, 1987a; Blamey \& Tartter, 1992). No significant changes in vowel performance were observed in the group data, although the $p$ value only just failed to reach significance $(p=$ 0.053). Vowel scores in the initial assessments were higher than the consonant scores. This relatively high performance coupled with the small number of vowels sampled (16 trials) may have contributed to the lack of a significant increase. Both the WSP and MSP encoding strategies are designed to convey the first and second formants of vowels. Previous studies have indicated improvements in vowel production with implant use. Osberger et al. (1991) observed a greater increase in the use of high, front vowels in children using the 22-electrode cochlear implant (WSP processors) than in children using the $3 \mathrm{M} /$ House single-channel cochlear implant or the Tactaid II after 1 yr of device use. A study by Tye-Murray and Kirk (1993) of children aged from 3 yr 11 mo to 7 yr 5 mo using the 22-electrode cochlear implant with either the F0F1F2 strategy or the multipeak strategy, similarly found an increase in the production and accuracy of high, front vowels and diphthongs after 24 to 36 mo implantation. In contrast, Geers and Tobey (1992) observed increases in accuracy for back vowels and diphthongs but not for front vowels.

As expected, performance on the articulation test was significantly associated with performance on the intelligibility test for the nine subjects who completed both tests. This is compatible with previous studies, indicating that better segmental pro- duction is associated with better intelligibility (Maassen \& Povel, 1985; Monsen, 1978).

Can the variability in speech production performance among patients in this study be accounted for by factors such as speech perception and age at implantation? Data on more children and adolescents need to be gathered before the relationships between various predictive factors and gains in speech production can be clearly indicated. Note, however, that four of the patients in this study were over the age of $17 \mathrm{yr}$ at implantation and three of these showed significant improvement on the sentence intelligibility test and one significantly improved on the articulation test. These results show clearly that it is not impossible for older deaf adolescents and adults to improve their speech production skills.

In this study there was no clear-cut relationship between gains in speech production and speech perception performance on a sound-alone word recognition task. Significant gains in production occurred for some patients with poor word-recognition skills (e.g., 62, 63, 93, and 104) as well as for those with the best perception skills. Improvements in speech production cannot therefore be solely attributable to implant use. It is likely that other factors such as the use of tactile and visual cues and speech therapy in the educational setting and in the Cochlear Implant Clinic were important in influencing production changes. Without a control group the relative contribution of the implant cannot be isolated from the influence of these other factors. Studies have shown that better prosody in speech production can improve speech intelligibility (Maassen \& Povel, 1985; Oster \& Martony, 1981). It is probable that prosodic cues provided by the implant contributed to some extent to gains in intelligibility for patients 63, 93, and 104. For patients 62 and 63 improvements in articulation would have been largely attributable to speech production training, but the implant at least allowed all speech sounds to be audible, including the softer unvoiced fricatives which were inaudible prior to implantation.

There was also no clear-cut relationship between duration of implant use and speech production changes. For both articulation and intelligibility measures the patients with the greatest duration of implant use did not consistently show the greatest gains in production. Furthermore, preoperative performance in articulation and intelligibility did not appear to be related to changes in production postimplantation.

\section{Summary}

This study examined the speech production skills of children aged $8 \mathrm{yr}$ and over, adolescents, and 
prelinguistically deafened adults using the 22-electrode cochlear implant. There are lower expectations for improvements in speech production for older hearing-impaired subjects with early onset of deafness. It was therefore encouraging to find a significant increase in the group mean intelligibility postimplant with roughly half of the subjects showing significant gains over time. Significant increases in the group mean total, consonant and consonant blend scores were observed postimplant on an articulation test, with half of the patients significantly improving postimplantation. Improvements were found for most place, manner, and voicing categories of consonants, consistent with perceptual studies, showing that this information is available in the auditory signal. These data are in accord with previous studies detailing increased speech production performance with implant use in younger groups of children. Improvements cannot be attributed unam-

APPENDIX: Fisher-Logemann Test of Articulation Competence.

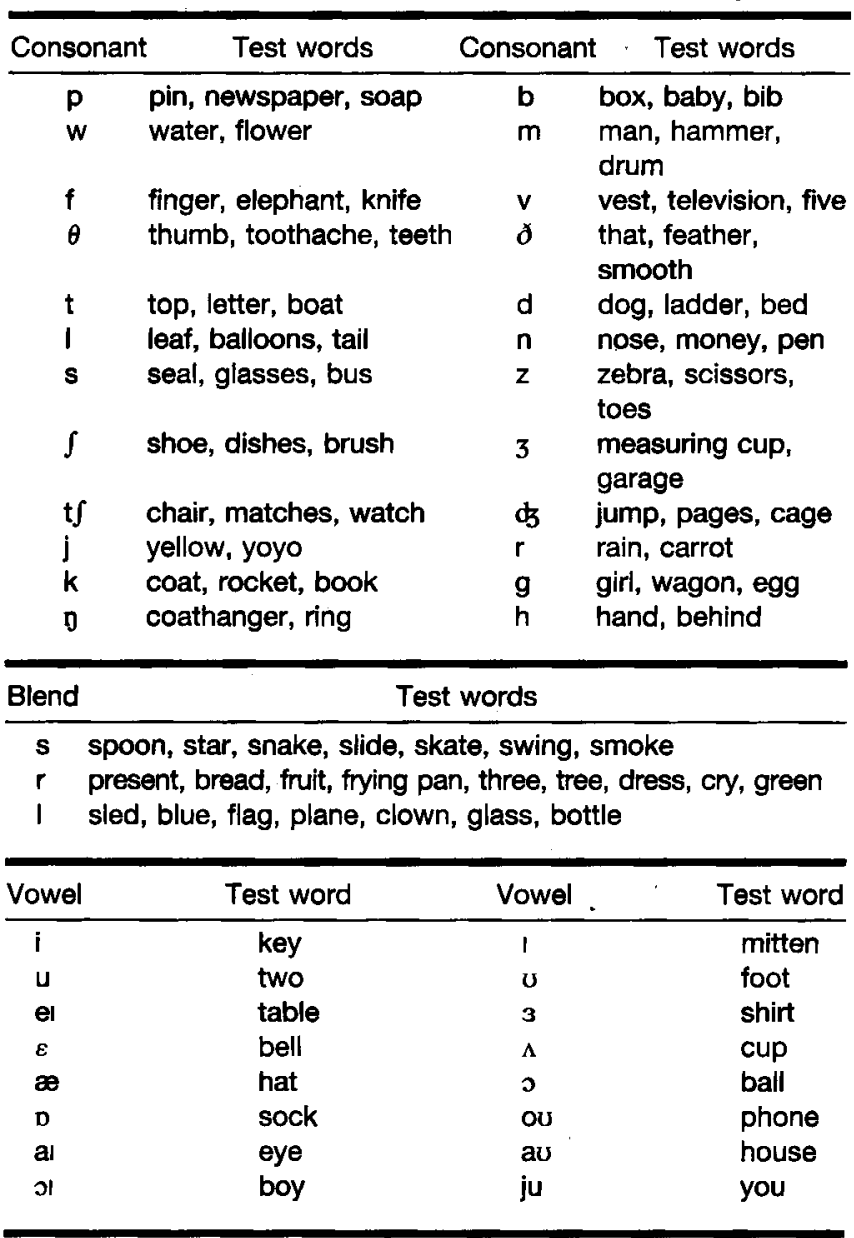

biguously to implant use since no control group was used in this clinical work. Further research with larger numbers of patients will indicate whether or not the findings for this group of subjects are typical of older children and adolescents in general.
Not every patient improved. Some patients demonstrated signs of plateauing at performance levels less that $100 \%$, and others showed little change with increased experience with the implant. Future research on larger groups of younger and older children and adolescents will be necessary to clarify the role of perception and other variables in predicting speech production performance.

\section{ACKNOWLEDGMENTS:}

The authors gratefully acknowledge the financial support of the Lions International Deafness Research Fellowship, the National Health and Medical Research Council of Australia, the Commonwealth Department of Employment, Education and Training and the Australian Research Council through the Human Communication Research Centre, and the Australian Bionic Ear and Hearing Research Institute. Many thanks also to the parents of the children involved and the teachers at Glendonald School for Deaf Children, St. Mary's School for Children with Impaired Hearing, Westbourne Grammar School, the deafness unit at Banksia College and Yarra Valley School Hearing Unit as well as the teachers working with children in mainstream educational settings. The authors are grateful for the assistance of the listeners, Julia Sarant, Karyn Galvin, Gary Rance and Rodney Hollow in obtaining reliability estimates.

Support for one of the authors, Dr. E. Tobey, was supplied by an Academic Research Enhancement Award from the National Institutes of Health (R15 DC 00037) and a Visiting Scholar Award from the University of Melbourne.

Address for correspondence: Ms. P. Dawson, The Australian Bionic Ear and Hearing Research Institute, 384-388 Albert St., East Melbourne, Victoria 3002, Australia.

E. A. Tobey is on sabbatical leave from the Department of Communication Disorders, Louisiana State University Medical Center, New Orleans, Louisiana.

Received November 22, 1993; accepted June 2, 1995

\section{REFERENCES}

Anthony, A., Bogle, D., Ingram, T. T., \& McIsaac, M. W. (1971). The Edinburgh Articulation Test. Edinburgh: Churchill Livingston.

Blamey, P. J., Dowell, R. C., Brown, A. M., Clark, G. M., \& Seligman, P. M. (1987a). Vowel and consonant recognition of cochlear implant patients using formant-estimating speech processors. Journal of the Acoustical Society of America, 82, 48-57.

Blamey, P. J., Dowell, R. C., Clark, G. M., \& Seligman, P. M. (1987b). Acoustic parameters measured by a formant-estimating speech processor for a multiple-channel cochlear implant. Journal of the Acoustical Society of America, 82, 38-47.

Blamey, P. J., \& Tartter, V. C. (1992). Fricative perception bycochlear implant users. Proceedings of 4th Australian International Conference on Speech Science and Technology (pp. 678-683). Brisbane.

Boothroyd, A. (1985). Auditory capacity and the generalization of speech skills. In J. Lauter (Ed), Speech planning and production in normal and hearing-impaired children, ASHA Reports, 15, 8-14.

Brannon, J. (1964). Visual feedback of glossal motions and its influence on the speech of deaf children. Doctoral dissertation, Northwestern University, Chicago.

Busby, P., Roberts, S., Tong, Y., \& Clark G. M. (1991). Results of speech perception and speech production training for three 
prelingually deaf patients using a multiple-electrode cochlear implant. British Journal of Audiology, 25, 291-302.

Busby, P. A., Tong, Y. C., Roberts, S. A., Altidis, P. M., Dettman, S. J., Blamey, P. J., Clark, G. M., Watson, R. K., Nicholls, G. H., Dowell, R. C., \& Rickards, F. W. (1989). Results for two children using a multiple-electrode intracochlear implant. Journal of the Acoustical Society of America, 86, 2088-2102.

Byrne, D. (1977). The speech spectrum: Some aspects of its significance for hearing aid selection and evaluation. British Journal of Audiology, 11, 40-46.

Carr, J. (1953). An investigation of the spontaneous speech sounds of five-year-old deaf-born children. Journal of Speech and Hearing Disorders, 18, 22-29.

Clark, G. M., Blamey, P. J., Busby, P. A., Dowell R. C., Franz, B. K.-H., Musgrave, G. H., Nienhuys, T. G., Pyman, B. C., Roberts, S. A., Tong, Y. C., Webb, R. L., Kuzma, J. A., Money, D. K., Patrick, J. F., \& Seligman, P. M. (1987). A multipleelectrode cochlear implant for children. Archives of Otolaryngology Head and Neck Surgery, 113, 825-828.

Dowell, R. C., Dawson, P. W., Dettman, S. J., Shepherd, R. K., Whitford, L. A., Seligman, P. M., \& Clark, G. M. (1991). Multichannel cochlear implantation in children: A summary of current work at the University of Melbourne. American Journal of Otology, 12(Suppl.), 137-143.

Fisher, H., \& Logemann, J. (1971). Test of Articulation Competence. New York: Houghton and Mifflin.

Forner, L., \& Hixon, T. (1977). Respiratory kinematics in profoundly hearing-impaired speakers. Journal of Speech and Hearing Research, 20, 373-408.

Geers, A. E., \& Tobey, E. A. (1992). Effects of sensory aids on the development of speech production skills in children with profound hearing impairment. Volta Review, 94, 135-163.

Geffner, D. (1980). Feature characteristics of spontaneous speech production in young deaf children. Journal of Communication Disorders, 13, 443-454.

Gold, T. (1980). Speech production in hearing-impaired children. Journal of Communication Disorders, 13, 397-418.

Hudgins, C., \& Numbers, F. (1942). An investigation of the intelligibility of the speech of the deaf. Genetic Psychology Monographs, 25, 289-392.

John, J., \& Howarth, H. (1965). The effect of time distortions on the intelligibility of deaf children's speech. Language and Speech, 8, 127-134.

Kirk, K. I., \& Hill-Brown, C. (1985). Speech and language results in children with a cochlear implant. Ear and Hearing, 6(Suppl.), 36-47.

Maassen, B., \& Povel, D. (1985). The effect of segmental and suprasegmental corrections on the intelligibility of deaf speech. Journal of the Acoustical Society of America, 78, 877-886.

Markides, A. (1970). The speech of deaf and partially hearing children with special reference to factors affecting intelligibility. British Journal of Disorders of Communication, 5, 126-140.

McGarr, N. S. (1983). The intelligibility of deaf speech to experienced and inexperienced listeners. Journal of Speech and Hearing Research, 26, 451-458.

McGarr, N. S. (1987). Communication skills of hearing-impaired children in schools for the deaf. In H. Levitt, N. S. McGarr, \& D. Geffner (Eds.), Development of language and communication skills in hearing-impaired children. ASHA Monographs, 26, 91-107.

Metz, D., Whitehead, R., \& Mashie, J. (1982). Physiological correlates of the speech of the deaf: A preliminary view. In D. G. Sims, G. G. Walter, \& R. L. Whitehead (Eds.), Deafness and communication: assessment and training. Baltimore: Williams and Wilkins.
Monsen, R. (1978). Toward measuring how well hearing impaired children speak. Journal of Speech and Hearing Research, 21, 197-219.

Nickerson, R. (1975). Characteristics of the speech of deaf persons. Volta Review, 77, 342-362.

Nober, H. (1967). Articulation of the deaf. Exceptional Children, 33, 611-621.

Osberger, M. J., Maso, M., \& Sam, L. K. (1993). Speech intelligibility of children with cochlear implants, tactile aids, or hearing aids. Journal of Speech and Hearing Research, 36, 186-203.

Osberger, M. J., \& McGarr, N. (1982). Speech production characteristics of the hearing impaired. In N. Lass (Ed.), Speech and language: advances in basic research and practice, New York: Academic Press.

Osberger, M., Robbins, A., Berry, S., Todd, S., Hesketh, L., \& Sedey, A. (1991). Analysis of the spontaneous speech samples of children with a cochlear implant or tactile aid. American Journal of Otology, 12(Suppl.), 151-164.

Öster, A.-M., \& Martony, M. J. (1981). Talfel och dess effekter tua expt. (Technical Report, pp. 1-24). Stockholm: Royal Institute of Technology,

Plant, G. (1984). A diagnostic speech test for severely and profoundly hearing-impaired children. Australian Journal of Audiology, 6, 1-9.

Shaw, S., \& Coggins, T. (1991). Interobserver reliability using the Phonetic Level Evaluation with severely and profoundly hearing-impaired children. Journal of Speech and Hearing Research, 34, 989-999.

Shriberg, L. D., \& Lof, G. L. (1991). Reliability studies in broad and narrow phonetic transcription. Clinical Journal of Linguistics and Phonetics, 5, 225-279.

Skinner, M. W., Holden, L. K., Holden, T. A., Dowell, R. C., Seligman, P. M., Brimacombe, J. A., \& Beiter, A. L. (1991). Performance of postlinguistically deaf adults with the wearable speech processor (WSP III) and mini speech processor (MSP) of the Nucleus multi-electrode cochlear implant. Ear and Hearing, 12, 3-22.

Smith, C. (1975). Residual hearing and speech production in deaf children. Journal of Speech and Hearing Research, 18, 795-811.

Staller, S. (1990). Perceptual and productive abilities in profoundly deaf children with multichannel cochlear implants. Journal of the American Academy of Audiology, 1, 1-3.

Staller, S., Gibson, A., Beiter, A., Chute, P., Goin, D., Portmann, M., \& Schwartzman, G. (1991). Cochlear implants in children: Results and complications. In I. Kaugman Arenbreg (Ed.), Proceedings of the 3rd International Symposium and Workshops on the Surgery of the Inner Ear (pp. 1-4). Amsterdam: Kugler and Ghedini Publications.

Stoel-Gammon, C., \& Dunn, C. (1985). Normal and disordered phonology in children. Austin, TX: Pro-Ed.

Tobey, E., Angelette, S., Murchison, C., Nicosia, J., Sprague, S., Staller, S., Brimacombe, J., \& Beiter, A. (1991a). Speech production in children receiving a multichannel cochlear implant. American Journal of Otology, 12(Suppl.), 164-172.

Tobey, E., \& Hasenstab, S. (1991). Effects of a Nucleus multichannel cochlear implant upon speech production in children. Ear and Hearing, 12(Suppl.), 48-54.

Tobey, E., Pancamo, S., Staller, S., Brimacombe, J., \& Beiter, A. (1991b). Consonant production in children receiving a multichannel cochlear implant. Ear and Hearing, 12, 23-31.

Tye-Murray, N., \& Kirk, K. I. (1993). Vowel and diphthong production by young users of cochlear implants and the relationship between the phonetic level evaluation and spontaneous speech. Journal of Speech and Hearing Research, 36, 488-502.

Whitehead, R., \& Barefoot, S. (1980). Some aerodynamic characteristics of plosive consonants produced by hearing impaired speakers. American Annals of the Deaf, 125, 366-373. 


\section{University Library}

\section{- M M I N E R VA A gateway to Melbourne's research publications}

Minerva Access is the Institutional Repository of The University of Melbourne

\section{Author/s:}

Dawson, P. W.;Blamey, P. J.;Dettman, S. J.;Rowland, L. C.;Barker, E. J.;Tobey, E. A.;Busby, P. A.; Cowan, R. C.

Title:

A clinical report on speech production of cochlear implant users

Date:

1995

\section{Citation:}

Dawson, P. W., Blamey, P. J., Dettman, S. J., Rowland, L. C., Barker, E. J., Tobey, E. A., et al. (1995). A clinical report on speech production of cochlear implant users. Ear and Hearing, December, 16(6), 551-561.

Persistent Link:

http://hdl.handle.net/11343/27479 